Oecologia, 1988, Volume 75, Issue 1, Pages 94-98

ISSN: (print 0029-8549); (online 1432-1939)

DOI: $10.1007 / \mathrm{BF} 00378819$

The original publication is available at www.springerlink.com

http://www.springerlink.com/content/100458/

http://www.springerlink.com/content/xg77819667161107/fulltext.pdf

(C) 1988 Springer-Verlag

\title{
Complex predator-prey interactions and predator intimidation among crayfish, piscivorous fish, and small benthic fish
}

\section{Frank J. Rahel and Roy A. Stein}

\begin{abstract}
Summary. Predator-prey interactions were studied among a small prey fish (the johnny darter Etheostoma nigrum) and two predators (crayfish Orconectes rusticus and small-mouth bass Micropterus dolomieui) with complementary foraging behaviors. When only smallmouth bass were present, darters reduced activity to $6 \%$ of control rates and spent most of the time hiding under tile shelters. When only crayfish were present, darter activity and shelter-use were similar to controls. When both crayfish and bass were present, an interaction occurred. Darters, normally inactive in the presence of bass, were often forced to move by approaching crayfish and thus activity increased to $19 \%$ of control rates. Also, darters were often evicted from shelters by intruding crayfish. Thus, crayfish increased the vulnerability of small fish to bass by evicting them from shelters and causing increased activity. Conversely, bass increased the vulnerability of small fish to crayfish by forcing these fish to seek cover under shelters occupied by crayfish. Intimidation effects of bass on darters last for some time. After a 30-min exposure to bass, darters showed reduced activity and increased shelter use lasting at least $24 \mathrm{~h}$ after the bass was removed. Thus predators, through intimidation, can influence prey behavior even though the predators are no longer present.
\end{abstract}

Intimidation by predators is an important factor influencing the spatial distribution and behavior of prey organisms (Charnov et al. 1976, Stein 1979). Prey may be forced to seek shelter, switch microhabitats, or restrict activity, all of which can reduce foraging rates and growth (Milinski and Heller 1978; Werner et al. 1983; Holmes 1984; Power et al. 1985). Different predators may interact in their effects on prey organisms. For example, the activities of one predator may increase prey encounter rates for other predators (Charnov et al. 1976). Such an interaction has been proposed for the group of large vertebrate predators preying on small mammals in the Sierra Madra foothills of California. Small mammals avoid predators that hunt beneath bushes or dense cover by moving into open areas, thereby becoming more vulnerable to avian predators. When prey flee avian predators by returning to cover, they become more vulnerable to mammalian predators (Charnov et al. 1976).

In aquatic habitats, crayfish, large piscivorous fishes, and small benthic fishes, such as darters, comprise a system where interactions among predators may be important. The prey (small benthic fishes) should seek shelter and reduce activity to avoid predation by piscivorous fishes such as smallmouth bass Micropterus dolomieui. Predation by bass on small fishes such as darters is well-documented (Page 1983). Less is known about interactions between crayfish and small benthic fishes despite the fact that both use similar substrates as shelter. Although typically considered to be opportunistic scavengers, crayfish will seize and eat darters if they encounter them in a confined area (Rahel, personal observation). To avoid predation by crayfish, benthic fishes may have to become more active or evacuate shelter. The latter response may be particularly important when crayfish also seek shelter to avoid being eaten by bass. Thus, crayfish may increase the vulnerability of small fish to bass predation by evicting them from shelter or forcing 
them to move frequently. Conversely, bass may increase the vulnerability of small fish to crayfish predation by forcing these fish to seek cover under shelters occupied by crayfish. Mutual enhancement of prey availability could result from the complementary foraging behaviors of bass and crayfish.

Another aspect of predator intimidation is the degree to which prey behavior remains affected after the predator is gone. The latency period (i.e., the time between the removal of the predator and the resumption of normal activities) is important because prey remaining unnecessarily hidden or inactive cannot engage in important activities such as feeding or seeking mates (Morse 1980). In aquatic systems, small prey fish show strong changes in activity and microhabitat use in the presence of large piscivorous fish (Mittelbach and Chesson 1987). It is not known, however, how long such prey remain intimidated after the predator is gone.

The objectives of our study were to determine if bass and crayfish mutually enhance prey availability due to their complementary foraging behaviors and to examine the residual effects of predator intimidation on the behavior of small prey fish.

\section{Materials and methods}

\section{Predator-prey interactions among crayfish, bass, and darters}

To determine if crayfish and smallmouth bass mutually enhance prey availability, we compared shelter use, activity, and survival of johnny darters Etheostoma nigrum exposed to one of four treatments: I) no predator, II) crayfish present, III) smallmouth bass present, and IV) both crayfish and smallmouth bass present. We selected johnny darters because they are common in pool or backwater areas where smallmouth bass and crayfish also are present (Page 1983). The crayfish species used was Orconectes rusticus, a large, aggressive species that has recently undergone a considerable range expansion due to human introductions (Butler and Stein 1985).

Experiments were conducted in 120-L tanks (bottom area $90 \times 37 \mathrm{~cm}$ ) containing a layer of small gravel to provide a natural substrate. Shelter was provided by four opaque Plexiglas tiles measuring $10 \times 10 \mathrm{~cm}$ and propped up at one end by a $2.5-\mathrm{cm}$ piece of pipe. The sloping tiles provided a refuge from predation by bass but permitted access by crayfish. Experiments were done at $18-20 \mathrm{C}$ with a 16:8 h (light:dark) photoperiod.

On the morning before an experiment, eight johnny darters (total length 36-54 mm) were placed in each of four tanks and fed live midge larvae. At the same time, bass were fed minnows and crayfish were fed commercial trout food. No additional food was provided during the rest of the experiment. After $24 \mathrm{~h}$, one smallmouth bass and/or four crayfish (carapace length $25-30 \mathrm{~mm}$ ) were added to the experimental tanks depending on the treatment. The density of crayfish $\left(12 / \mathrm{m}^{2}\right)$ was within the range of densities reported for $O$. rusticus in a variety of habitats (Momot et al. 1978). Control tanks received no predators. Three smallmouth bass (total lengths 85, 110, and 130 $\mathrm{mm}$ ) were used, with each bass used in about the same number of trials.

Darters respond to the presence of bass by reducing activity and spending more time under shelters. As an index of activity, the number of moves by darters was recorded $6 \mathrm{~h}$ after the addition of the predator(s). Darters typically move by hopping off the bottom; each time a fish left the bottom was counted as a single move. Observations of activity ( 3 min each) were made on 10 randomly selected darters to yield 30 min of observations per trial. During this period, we also recorded the percentage of time darters spent hiding under shelters. Each 30-min period was treated as one datum. Each treatment was replicated 16-17 times using a new group of johnny darters. To determine if activities of the two predators mutually enhanced predation rates, we 
counted the number of darters surviving after $24 \mathrm{~h}$.

To determine if there was an interaction involving the effect of the two predators on darter behavior and survival, data were analyzed by two-way ANOVA. To achieve normality, activity data were transformed by taking the logarithm (number of moves +1 ) and shelter-use data by using an arcsine transformation. If the ANOVA was significant, paired t tests were used to compare treatments. Null hypotheses were rejected at reduced alpha levels $(\alpha=0.05 / \mathrm{n}$ where $\mathrm{n}$ equals the number of pairwise comparisons) to correct for experimentwise error (Bonferroni's Inequality, Snedecor and Cochran 1980). There were no differences in the response of darters to individual bass (one-way ANOVA, $P>0.05$ ) and therefore data from the three bass were combined for analysis.

\section{Residual effects of predator intimidation}

Residual effects of predator intimidation were examined by monitoring the behavior of darters after a 30-min exposure to smallmouth bass. The experimental set-up was similar to the previous experiments except that 3 larger tanks $(260 \mathrm{~L}, 120 \times 60 \mathrm{~cm}$ bottom area) and 8 tiles per tank were used. On the morning before an experiment, five johnny darters (total length $44-54 \mathrm{~mm}$ ) were placed into each tank and fed live midge larvae. No further feeding was done. After $24 \mathrm{~h}$, a smallmouth bass was placed into the tank for $30 \mathrm{~min}$, then removed. Darter movements and shelter use were observed for 10-min periods starting $30 \mathrm{~min}$ before the predator was introduced, while the predator was present, and at $0.5,1,2,3,4,5,6,24 \mathrm{~h}$ after the predator was removed. Three smallmouth bass (total length $125-140 \mathrm{~mm}$ ) were used as predators, with each bass used in six trials. Bass were added and removed by dipnet. This disturbance was simulated in control tanks by moving an empty net around the tank for $15 \mathrm{~s}$.

During each observation period, each of the five darters was watched for two different 1-min intervals. The 10 min of observation per observation period were treated as a single datum. Activity and shelter-use were quantified as in the previous experiment. For each time period, activity and shelter-use were compared between predator-exposed and non-predator exposed darters using the Mann-Whitney $U$ test. There were no differences in the response of darters to individual bass (Kruskal-Wallis test, $P>0.05$ ); therefore, data from the three bass were combined in the analysis.

\section{Results \\ Predator-prey interactions among crayfish, bass, and darters}

Johnny darters responded to the presence of smallmouth bass by reducing activity and increasing shelter use (Fig. 1A, B). Crayfish, by themselves, had little effect because darter activity and shelter use were similar whether no predators or only crayfish were present (pairwise comparison of treatments I and II, Fig. 1A, B). There was, however, a significant interaction between the effects of crayfish and smallmouth bass on darter behavior (Table 1). When only bass were present, darters showed little activity (mean number of moves was $6 \%$ of controls). When both bass and crayfish were present, darters were significantly more active than with only bass present (mean number of moves was $19 \%$ of controls) as a consequence of avoiding crayfish. Often, bass swam directly over motionless darters that were cryptically colored against the gravel bottom. Moving darters, however, quickly attracted the attention of bass. Although inactivity would be 
advantageous in reducing bass predation, darters were frequently forced to move out of the path of crayfish. Crayfish often chased darters with open chelae, and although no captures were observed during this experiment, one capture was observed during a trial run.

Darters also spent less time hiding under shelter when crayfish and bass were present than when only bass were present (Fig. IB). This again reflects the need for darters to avoid crayfish. Darters were frequently observed to leave a shelter when a crayfish entered. Although evicted darters usually moved to a nearby shelter or re-entered the opposite side of the same shelter, the increased movement and exposure increased their visibility to bass.
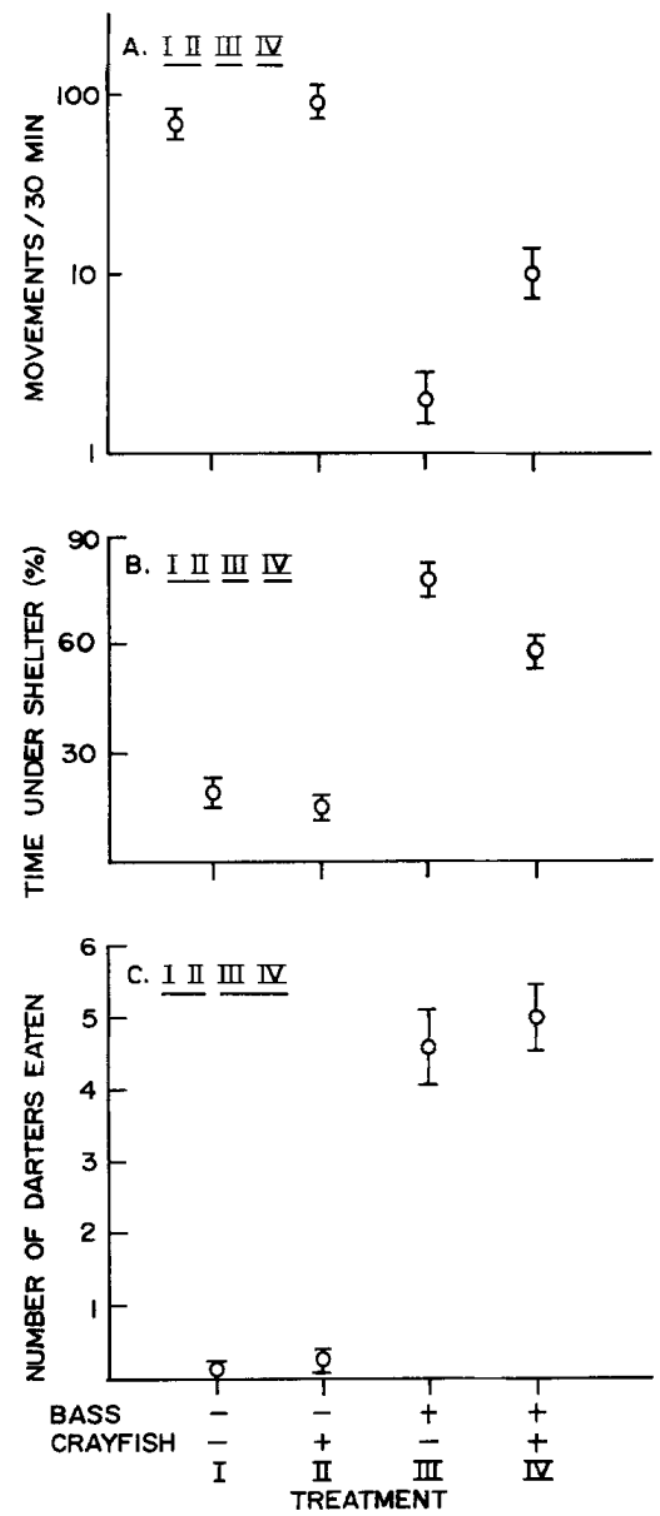

Fig. 1. Comparison of activity (A), the percentage of time spent under shelter (B), and the number of darters eaten (C) where darters were exposed to no predators (I), crayfish only (II), small-mouth bass only (III), or both crayfish and smallmouth bass (IV). Shown are the mean + SE. Underlined treatments are not significantly different $(P \geq 0.05) . N=$ 16 for treatments I and II, $N=17$ for treatments III and IV 
Crayfish did not respond to the bass. Whether or not bass were present, an average of one of four crayfish was under shelter after $6 \mathrm{~h}$ (t test, $P>0.05$ ). This lack of intimidation was expected because crayfish of the size used in the experiments (carapace length $25-30 \mathrm{~mm}$ ) were too large to be consumed by 85-130 mm bass (Stein 1977).

The increase in activity and decrease in shelter use when both bass and crayfish were present suggested that predation rates might be higher with both predators present than when either predator acted alone. Although more darters were eaten when both predators were present, this difference was not significant (Fig. 1C, Treatments III and IV). However, the consistent trends among the three response variables (increased activity, decreased shelter-use, and the tendency for greater predation rates when bass and crayfish were present together) suggests that these two predators could mutually enhance prey encounter rates in nature.

Table 1. Summary of analysis of variance for the effects of two predators on the activity, shelter-use, and survival of johnny darters when exposed to smallmouth bass and crayfish. Activity data were log transformed and shelter-use data arcsin transformed as described in the text

\begin{tabular}{lrrrl}
\hline Source of Variation & df & $\begin{array}{l}\text { mean } \\
\text { square }\end{array}$ & \multicolumn{1}{l}{$F$} & $P$ \\
\hline Movements/30 min & & & & \\
Bass & 1 & 24.13 & 140.93 & $<0.01$ \\
Crayfish & 1 & 2.77 & 16.18 & $<0.01$ \\
Interaction & 1 & 1.52 & 8.88 & $<0.01$ \\
Residual & 59 & 0.17 & & \\
\% Shelter-use & & & & \\
Bass & 1 & 12.47 & 161.86 & $<0.01$ \\
Crayfish & 1 & 0.62 & 8.09 & $<0.01$ \\
Interaction & 1 & 0.33 & 4.33 & $<0.05$ \\
Residual & 59 & 0.08 & & \\
Number of darters eaten & & & & \\
Bass & 1 & 150.92 & 57.64 & $<0.01$ \\
Crayfish & 1 & 0.13 & 0.05 & $\mathrm{~ns}$ \\
Interaction & 1 & 0.13 & 0.05 & $\mathrm{~ns}$ \\
Residual & 62 & 2.62 & & \\
\hline
\end{tabular}

ns $=$ not significant at $P \leq 0.05$

\section{Residual effects of predator intimidation}

Residual effects of predator intimidation were followed after a 30-min exposure of darters to a smallmouth bass. Before the bass was added, darters in the two treatments were active and showed little use of shelters (Fig. 2 A, B). Whereas darters in the control treatment continued this behavior throughout the next $24 \mathrm{~h}$, predator-exposed darters greatly decreased their activity and increased shelter-use while the bass was present and continued to show such behavioral changes $24 \mathrm{~h}$ after the predator was removed (Fig. 2 A, B). Time required to resume normal behavior was greater than $24 \mathrm{~h}$ since predator-exposed darters were still significantly less active and spent more time under shelters than control darters when the experiment was terminated.

Conceivably, in those replicates in which darters were eaten, the prolonged depression of activity could be due to an alarm pheromone released from the skin of injured conspecifics (Smith 1979). However, behavioral response to these alarm chemicals lasts only 60 min (Smith 1979), 
obviously less than the $24 \mathrm{~h}$ we observed. In addition, behavioral response was similar for trials in which predation did $(N=6)$ and did not occur $(N=12$, Mann-Whitney $\mathrm{U}$ test, $P>0.05)$. Thus, inactivity and increased shelter use by darters was not a reaction to alarm chemicals, but appeared to be a reaction to the threat of predation.

\section{Discussion}

When predatory fish are present, small prey fish should change their behavior to avoid predation. As in the present study, this might involve moving to protective habitats (Werner et al. 1983; Power et al. 1985) or reducing activity (Stein and Magnuson 1976; Dill and Fraser 1985). However, when predators that forage in crevices are present, prey may be forced to increase activity and evacuate shelters to avoid these predators. Thus predators with complementary foraging behaviors can interact to influence prey availability. Such an interaction has been reported for coral reef fish feeding on prey flushed out of crevices by octopuses and moray eels (Diamant and Shpigel 1985). The eels and octopuses, due to their malleable body form, gain access to crevices that most fish cannot enter. Fishes such as groupers (Serranidae) have learned to follow eels or octopuses and prey on small fish or crustaceans flushed out of hiding places. It is not known, however, how much the eels or octopuses benefit by capturing prey chased into crevices by the groupers.
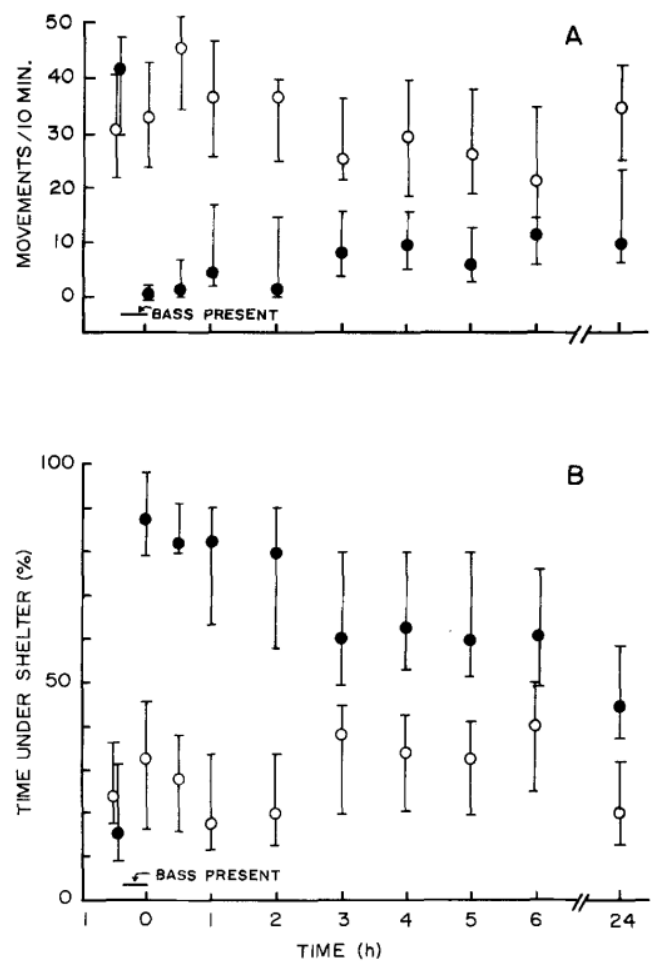

Fig. 2. Activity and shelter-use by johnny darters through $24 \mathrm{~h}$ after a sham treatment (o) or after a 30-min exposure to small-mouth bass $(\cdot)$ at time 0 . Shown are the median and $95 \%$ confidence intervals based on Walsh averages. $N=18$ for both treatments

Interactions among predators may be asymmetric. Bass are highly efficient predators and 
probably benefit more from the activities of crayfish (e.g. dislodging darters or increasing darter movement) than crayfish benefit from the activities of bass (e.g. forcing darters to seek shelter). Such asymmetry in interactions among predators is not unusual, however. By following northern hogsuckers (Hypentilium nigrum) as they forage in a stream, young smallmouth bass are able to feed on otherwise cryptic prey fleeing from the hogsuckers (Rankin 1986). The bass have higher feeding rates than when foraging alone but the hogsuckers receive no apparent benefit from the bass. Similarly, some tropical birds are obligate army-ant followers and probably could not exist without the prey-flushing activities of the ants (Willis 1969). The ants, on the other hand, seem to receive little benefit from the hunting activities of the birds.

Interactions among crayfish, piscivorous fish, and small benthic fishes should be most intense where both predators are common and shelter is limiting. This would occur in pool areas of streams or in the littoral zone of lakes lacking rocky substrates. Oligotrophic, northern U.S. lakes being invaded by the crayfish Orconectes rusticus are prime sites where the interaction between crayfish and piscivorous fish could lead to increased predation and perhaps extirpation of vulnerable prey (Lorman and Magnuson 1978). These lakes often have extremely high densities of this crayfish $\left(25\right.$ adults $\left./ \mathrm{m}^{2}\right)$ in addition to abundant populations of predatory fish such as smallmouth bass or walleye (Stizostedion vitreum). Although predaton on fish eggs and destruction of macrophyte beds have been attributed to O. rusticus, no work has examined their effect on small benthic fishes.

Studies of prey response to predators have generally focused on the behavioral changes that occur while predators are present. Little is known about the residual effects of predator initimidation. Ideally, prey organisms should resume normal activities immediately after a predator has left an area. Mixed-species flocks of small, passerine birds returned to foraging activities within several minutes after being frightened by the overhead passage of a hawk (Morse 1973). Similarly, guppies (Poecilia reticulata) remained motionless for less than $10 \mathrm{~s}$ after a model of an avian predator was passed overhead (Seghers 1974). In contrast, darters showed anti-predator behaviors lasting at least $24 \mathrm{~h}$ after contact with smallmouth bass. Differences in latency periods make reflect differences in the perceived degree of predation risk. Avian predators move relatively quickly through an area and are usually visible from a distance. Once they have passed through an area, prey can resume normal activity without the concern that a stalking predator is nearby. Predatory fish such as bass, however, move slowly through the water and may be difficult to detect at a distance in structurally complex environments. Once such a predator is sighted, it will be difficult for prey hiding under shelter to know when it is safe to resume normal activity.

To minimize the loss of feeding and mating opportunities, prey should respond to predators in proportion to the risk of predation. In the simplest situation, age or size classes of prey respond differently to a common predator. For example, small notonectids (backswimmers), were most vulnerable to predators (adult notonectids) and reacted more strongly than intermediate-size notonectids to the presence of such predators (Sih 1982). Similarly, small crayfish reduced activity and increased shelter use more than larger crayfish in response to a bass predator (Stein and Magnuson 1976).

In more complex situations, prey need to evaluate and respond to a variable risk of predation. For example, adult tits (Parus caerules) feeding on nuts increased their scanning rates (and hence decreased feeding rates) as predation risk increased (Lendrem 1983). Juvenile coho salmon (Oncorhyncus kisutch) reduced their foraging distance when a model of a predator was presented (Dill and Fraser 1984). Reductions in foraging distances were proportional to the risk of 
predation (varied by altering the frequency of model presentation). In situations such as these where the predation risk varies, prey need to evaluate both the costs and benefits of anti-predator behaviors in order to react appropriately.

The ability to respond in proportion to the risk of predation has implications for the distribution and growth of small benthic fishes in nature. Where piscivorous fish are abundant, small benthic fishes should be relatively inactive and closely associated with refuges. Where piscivorous fish are scarce, prey fish should be more active and less associated with safe habitats. If crayfish are present in either situation, they may contribute to the vulnerability of small fishes such as darters by forcing them out of refuges. Complex interactions of this sort, where one predator actually enhances the vulnerability of prey to other predators, may be important in systems where predators with quite different foraging behaviors coexist.

\section{Acknowledgements}

For their assistance in the field and in the laboratory, we thank the members of the Ohio State Aquatic Ecology Group and especially Brett Johnson, Nicky Kontonickas, and Jeffrey Miner. Helpful comments on the manuscript were provided by Wayne Hubert, Gary Mittelbach and two anonymous reviewers. Elizabeth Ono Rahel assisted with field collections and drafted the figures. This work was made possible through a University Postdoctoral Fellowship to F.J. Rahel funded through the Graduate School of The Ohio State University.

\section{References}

Butler MJ IV, Stein RA (1985) An analysis of the mechanisms governing species replacement in crayfish. Oecologia (Berlin) 66:168-177

Charnov EL, Orians GH, Hyatt K (1976) Ecological implications of resource depression. Am Nat 110:247-259

Diamant A, Shpigel M (1985) Interspecific feeding associations of groupers (Teleostei: Serranidae) with octopuses and moray eels in the Gulf of Eilat (Aqaba). Env Biol Fish 13:153-159

Dill LM, Fraser AHG (1984) Risk of predation and the feeding behavior of juvenile coho salmon (Oncorhynchus kisutch). Behav Ecol Sociobiol 16:65-71

Holmes WG (1984) Predation risk and foraging behavior of the hoary marmot in Alaska. Behav Ecol Sociobiol 15:293-301

Lendrem DW (1983) Predation risk and vigilance in the blue tit (Parus caeruleus). Behav Ecol Sociobiol 14:9-13 Lorman JG,

Magnuson JJ (1978) The role of crayfish in aquatic ecosystems. Fisheries 3:8-10

Milinski M, Heller R (1978) Influence of a predator on the optimal foraging behavior of sticklebacks (Gasterosteus aculeatus L.). Nature 275:642-644

Mittelbach GG, Chesson PL (1987) Predation risk: indirect effects on fish populations. In: Kerfoot WC, Sih A (eds) Predation: direct and indirect impacts on aquatic communities. New England Press pp 315-332

Momot WT, Gowing H, Jones PD (1978) The dynamics of crayfish and their role in ecosystems. Am Midi Nat 99:10-35

Morse DH (1973) Interactions between tit flocks and sparrow-hawks Accipiter nisus. Ibis 115:591-593

Morse DH (1980) Behavioral mechanisms in ecology. Harvard University Press. Cambridge, Massachusetts, USA

Page LM (1983) Handbook of darters. T F H Publication, Inc. Neptune City, New Jersey, USA

Power ME (1984) Depth distribution of armored catfish: predator-induced resource avoidance? Ecology 65:523-528

Power ME, Mathews WJ, Stewart AJ (1985) Grazing minows, piscivorous bass, and stream algae: dynamics of a strong interaction. Ecology 66:1448-1456

Rankin ET (1986) Habitat selection by smallmouth bass in response to physical characteristics in a natural system. Trans Am Fish Soc 115:322-334

Seghers BH (1974) Geographic variation in the response of guppies (Poecilia reticulata) to aerial predators. Oecologia (Berlin) 14:93-98

Sih A (1982) Foraging strategies and the avoidance of predation by an aquatic insect Notonecta hoffmanni. Ecology 63:786-796

Smith RJF (1979) Alarm reaction of Iowa and Johnny darters (Etheostoma, Percidae, Pisces) to chemicals from injured con-specifics. Can J Zool 57:1278-1282

Snedecor GW, Cochran WG (1980) Statistical methods. Iowa State University Press. Ames, Iowa, USA

Stein RA (1977) Selective predation, optimal foraging, and the predator-prey interaction between fish and crayfish. Ecology 58:1237-1253

Stein RA (1979) Behavioral response of prey to fish predators. In: Stroud RH, Clepper H (ed) Predator-Prey Systems in Fisheries Management. Sport Fishing Institute, Washington, D.C., USA pp 343-353

Stein RA, Magnuson JJ (1976) Behavioral response of crayfish to a fish predator. Ecology 57:751-761 
Werner EE, Gilliam JF, Hall DJ, Mittelbach GG (1983) An experimental test of the effects of predation risk on habitat use in fish. Ecology 64:1540-1548

Willis EO (1969) On the behavior of five species of Rhegmatorhina, ant-following antbirds of the Amazon basin. Wilson Bulletin 81:363-395 